\title{
ST HELENA
}

Area: 419 sq. km

Population: 6700

Capital: Jamestown

Governor: F. E. Bako

St Helena was administered by the East India Company from 1659 and became a British colony in 1834. The Island of St Helena Constabulary was formed in 1869 and presently has about 40 personnel, plus 30 Special Constables for auxiliary work. 